\title{
STUDI PENEMPATAN DINDING GESER TERHADAP WAKTU GETAR ALAMI FUNDAMENTAL STRUKTUR GEDUNG
}

\author{
Fadlan Effendi $^{1}$, Wesli $^{2}$, Yovi Chandra ${ }^{3)}$, Said Jalalul Akbar ${ }^{4)}$ \\ Jurusan Teknik Sipil Universitas Malikussaleh \\ email: fadlaneffendi.civil@gmail.com ${ }^{1)}$,wesli@ unimal.ac.id ${ }^{2)}$ \\ yovicivil@gmail.com ${ }^{3)}$ jaakidani@gmail.com $^{4}$
}

DOI: http://dx.doi.org/10.29103/tj.v7i2.133

\begin{abstract}
Abstrak
Dinding geser adalah slab beton bertulang yang dipasang pada posisi vertikal pada sisi gedung tertentu yang berfungsi menambah kekakuan struktur dan menyerap gaya geser yang besar seiring dengan semakin tingginya struktur. Ketika dinding geser ditempatkan pada lokasi tertentu yang cocok dan strategis, dinding tersebut dapat digunakan secara ekonomis untuk menyediakan tahanan beban horisontal yang diperlukan. Penelitian bertujuan untuk mengetahui pengaruh variasi tata letak dinding geser terhadap waktu getar alami fundamental struktur gedung serta gaya geser dasar dan simpangan antar lantai yang terjadi dan gaya-gaya dalam pada bangunan akibat adanya beban gempa. Semua variasi dinding geser di analisis dengan bantuan program Extended Three-dimensional Analysis Building System (ETABS). Hasil penelitian ini waktu getar alami fundamanetal yang paling kecil terdapat pada model 5 dengan nilai sebesar 0,957 detik sedangkan yang paling besar terdapat pada model 3 sebesar 1,264 detik. Untuk nilai drift yang paling besar terdapat pada model 6 sebesar $30,322 \mathrm{~mm}$ sedangkan nilai yang paling kecil terdapat pada model 3 sebesar $12,128 \mathrm{~mm}$. Untuk nilai geser dasar hanya model 6 yang memenuhi syarat SNI 03-1726-2012 sedangkan yang lain tidak memenuhi sehingga harus dilakukan pembesaran gaya geser. Pemodelan simetris pada model 4, model 5, model 6 memiliki nilai gaya dalam yang kecil. Sehingga dari semua pemodelan dinding geser pada pemodelan simetris yang memenuhi semua syarat SNI 03-1726-2012 dan memiliki gaya-gaya dalam yang kecil.
\end{abstract}

Kata kunci: Dinding geser, waktu getar alami fundamental struktur

\section{Pendahuluan}

Indonesia termasuk negara yang rawan terhadap gempa sehingga setiap pembangunan khususnya pembangunan gedung bertingkat tinggi harus dirancang tahan dan kuat terhadap gempa karena semakin tinggi bangunan akan semakin rawan terhadap gempa. Untuk mereduksi beban gempa yang besar yang terjadi pada bangunan gedung bertingkat tersebut digunakan penggabungan dari beberapa sistem struktur.

Dinding geser (Shearwall) adalah slab beton bertulang yang dipasang dalam posisi vertikal pada sisi gedung tertentu yang diproporsikan untuk menahan kombinasi geser, momen, dan gaya aksial. Dinding geser adalah dinding struktur yaitu yang ditetapkan sebagai bagian dari sistem penahan gaya gempa yang juga berfungsi menambah kekakuan struktur dan menyerap gaya geser yang besar seiring dengan semakin tingginya struktur. Ketika dinding geser ditempatkan pada 
lokasi-lokasi tertentu yang cocok dan strategis, dinding tersebut dapat digunakan secara ekonomis untuk menyediakan tahanan beban horisontal yang diperlukan (Andalas, 2016)

Tujuan penelitian ini adalah untuk mengetahui besarnya waktu getar alami fundamental struktur gedung, gaya geser dasar dan simpangan antar lantai serta gaya-gaya dalam kolom tengah dan pinggir yang terjadi pada bangunan akibat adanya variasi terhadap penempatan dinding geser.

\section{Tinjauan Kepustakaan}

Jika terjadi bencana alam seperti gempa yang merupakan salah satu beban lateral, maka struktur di atasnya akan mengalami pergerakan secara vertikal maupun secara lateral, dibanding pergerakan vertikal pergerakan lateral akan memberikan beban kepada struktur yang dapat menyebabkan struktur runtuh (Juwana, 2005)

(Paulay \& Priestley, 1992) memperkenalkan tiga sistem struktur yang dapat digunakan untuk meningkatkan daya tahan gedung bertingkat terhadap gempa dengan parameter utama waktu getar alami struktur, yaitu sistem struktur rangka, sistem dinding struktural (dinding geser), dan sistem ganda yang merupakan gabungan struktur rangka dan dinding struktural (dinding geser). Perbedaan di antara ketiga macam sistem struktur tersebut berkaitan dengan kemampuan dalam menahan gaya lateral. Sistem gabungan berupa rangka dan dinding struktural dapat menahan gaya lateral yang lebih besar dibandingkan dengan kedua sistem lainnya.

\subsection{Pembebanan Struktur}

Beban merupakan gaya atau aksi lainnya yang diperoleh dari berat seluruh bangunan, penghuni, barang-barang yang ada di dalam bangunan gedung, efek lingkungan, selisih perpindahan dan gaya kekangan akibat perubahan dimensi. Perencanaan pembebanan pada struktur gedung terdiri atas beban mati, beban hidup, beban angin, dan beban gempa.

\subsection{Waktu getar alami fundamental struktur gedung}

Beban merupakan gaya atau aksi lainnya yang diperoleh dari berat seluruh bangunan, penghuni, barang-barang yang ada di dalam bangunan gedung, efek lingkungan, selisih perpindahan dan gaya kekangan akibat perubahan dimensi. Perencanaan pembebanan pada struktur gedung terdiri atas beban mati, beban hidup, beban angin, dan beban gempa.

Periode getar $\mathrm{T}$ adalah waktu yang diperlukan untuk menempuh satu putaran lengkap dari suatu getaran ketika terganggu dari posisi keseimbangan statis dan kembali ke posisi aslinya. Periode getar juga sering disebut secara lengkap dengan "periode getar alami struktur" (natural fundamental period), dimana istilah "alami" tersebut digunakan untuk menggambarkan setiap getaran untuk menekankan fakta bahwa hal tersebut merupakan properti alami dari struktur yang bergantung pada massa dan kekakuan yang bergetar secara bebas tanpa adanya gaya luar. 
Semakin besar periode getar alami fundamental pada struktur gedung maka semakin kecil gaya gempa yang diterima gedung tesebut, yang dapat dengan mudah kita pahami dari respon spektrum, seperti gambar dari FEMA 451B (2007) berikut ini:

\section{Equivalent Lateral Force}

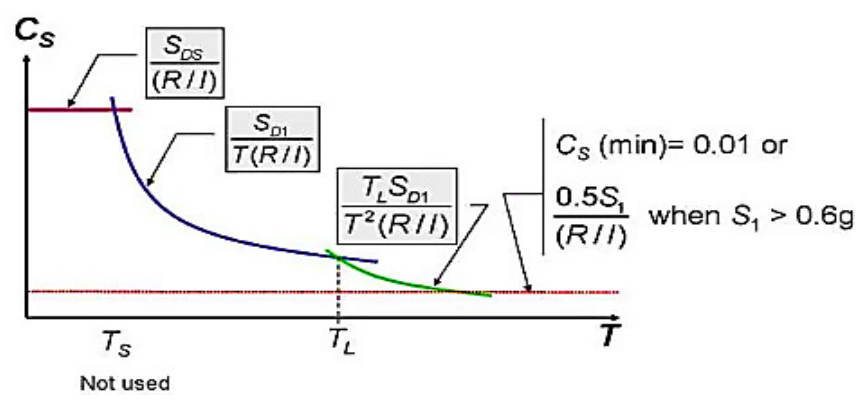

Gambar 1 Equivalent Lateral Force, ELF

Sumber: FEMA 451B, 2007

Perioda fundamental pendekatan (Ta), dalam detik, harus ditentukan dari persamaan berikut:

$$
T a=C_{t} \cdot h_{n}^{x}
$$

Keterangan:

$\mathrm{h}_{\mathrm{n}}$ adalah ketinggian struktur, dalam $(\mathrm{m})$, di atas dasar sampai tingkat tertinggi struktur, dan koefisien $\mathrm{Ct}$ dan $\mathrm{x}$.

Waktu getar pada perioda yang dihtung harus tidak melenihi dari persamaan:

$T=T a \cdot C u$

Keterangan:

$\mathrm{Cu}$ adalah nilai koefisien batas atas yang didapat berdasarkan nilai $\mathrm{S}_{\mathrm{D} 1}$

\subsection{Simpangan antar lantai (Drift)}

Gaya gempa lateral akan menghasilkan simpangan struktur dalam arah lateral. Dalam proses perencanaan struktur, maka simpangan lateral antar lantai tingkat (story drift) harus selalu diperiksa sesuai (SNI 03-1726-2012) untuk menjamin stabilitas struktur, mencegah kerusakan elemen-elemen nonstruktural, serta untuk menjamin kenyamanan penggunaan bangunan. Untuk sistem penahan gaya gempa yang terdiri dari hanya rangka momen pada struktur yang dirancang untuk kategori desain seismik D, E, atau F, simpangan antar lantai tingkat desain $(\Delta)$ tidak boleh melebihi $\Delta_{\mathrm{a}} / \rho$ untuk semua tingkat

\subsection{Elemen Struktur Dinding Geser (Shear wall)}

Dinding geser merupakan dinding yang dirancang untuk menahan gaya lateral akibat gempa bumi. Dinding geser yang efektif adalah yang bersifat kaku dan kuat. Dalam struktur bertingkat, dinding geser sangat penting, karena selain untuk mencegah kegagalan dinding eksterior, dinding geser juga mendukung beberapa lantai gedung dan memastikan bahwa struktur tidak runtuh akibat gerakan lateral dalam gempa bumi. 
Dalam merencanakan dinding geser, perlu diperhatikan bahwa dinding geser yang berfungsi untuk menahan gaya lateral yang besar akibat beban gempa tidak boleh runtuh akibat gaya lateral, karena apabila dinding geser runtuh karena gaya lateral maka keseluruhan struktur bangunan akan runtuh karena tidak ada elemen struktur yang mampu menahan gaya lateral. Oleh karena itu, dinding geser harus didesain untuk mampu menahan gaya lateral yang mungkin terjadi akibat beban gempa, dimana berdasarkan (SNI 03-2847-2013), tebal minimum dinding geser (td) tidak boleh kurang dari $100 \mathrm{~mm}$.

\subsection{Analisa Respon Spectrum Ragam}

(SNI 03-1726-2012) menyatakan bahwa, analisis harus dilakukan untuk menentukan ragam getar alami untuk struktur. Analisis harus menyertakan jumlah ragam yang cukup untuk mendapatkan partisipasi massa ragam terkombinasi sebesar paling sedikit 90 persen dari massa aktual dalam masing-masing arah horizontal orthogonal dari respons yang ditinjau oleh model. Kombinasi respons untuk geser dasar ragam (Vt) lebih kecil 85 persen dari geser dasar yang dihitung (V) menggunakan prosedur gaya lateral ekivalen, maka gaya harus dikalikan dengan $0,85=\frac{V}{V_{z}}$.

\section{Metode Penelitian}

Pendekatan penelitian yang dilakukan adalah pendekatan kuantitatif, karena nantinya hasil yang disajikan penelitian ini berupa angka atau bilangan yaitu merupakan hasil dari analisis struktur gedung dengan menggunakan program ETABS.

Data struktur yang digunakan pada penelitian ini adalah model struktur kombinasi rangka dengan dinding geser pada gedung 10 lantai pada bangunan simetris dengan fungsi sebagai hotel mengasumsikan berdiri diatas tanah lunak (SE) menggunakan mutu beton $35 \mathrm{Mpa}$. Dimensi kolom dan balok pada penelitian ini dilakukan preliminary dan didapat penampang kolom $70 \mathrm{~cm} \times 70 \mathrm{~cm}$, balok $40 \mathrm{~cm} \times 60 \mathrm{~cm}$ dan ring balok $30 \mathrm{~cm} \times 40 \mathrm{~cm}$. Dimensi dinding geser pada semua model sama yaitu tebal $30 \mathrm{~cm}$ agar hasil akibat penempatan dinding geser lebih akurat.

Beban mati pada bangunan mengacu pada PPIUG 1987, untuk beban hidup penelitian ini mengacu pada (SNI 03-2847-2013) dan untuk beban gempa pebelitian ini mangacu pada (SNI 03-1726-2012). Penempatan beban pada portal dilakukan pada program ETABS dan dilakukan pengkombinasian pembebanan sesuai (SNI 02-1726-2012).

\subsection{Pemodelan Struktur}

Jumlah model struktur dinding geser yang akan dimodelkan berjumlah 6 tipe pada bangunan yang sama yaitu portal terbuka dikombinasikan dengan dinding geser. Konfigurasi berbagai penempatan dinding geser pada bangunan diperlihatkan pada Gambar 2. 


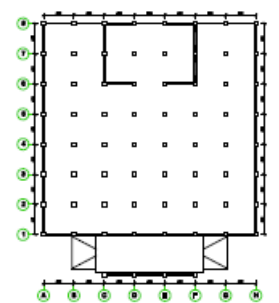

a. Model 1

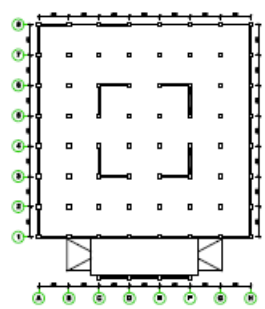

d. Model 4

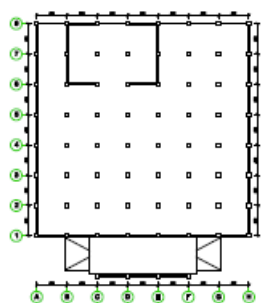

b. Model 2

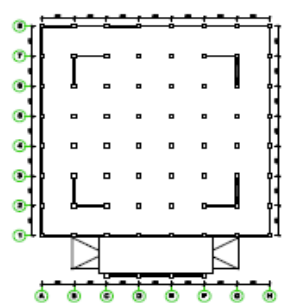

e. Model 5

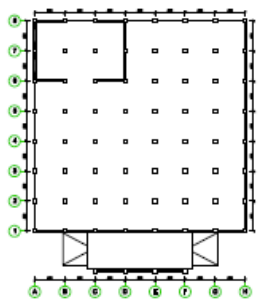

c. Model 3

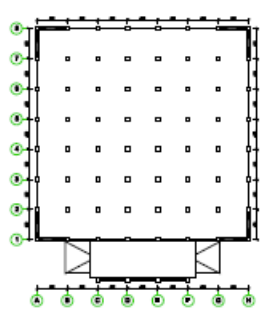

f. Model 6

Gambar 2 Layout shearwall

Data yang akan dianalisa adalah struktur portal 3D dengan pemodelan shearwall model 1, model 2, model 3, model 4, model 5, model 6 untuk arah X dan $\mathrm{Y}$ seperti gambar 2 yang menggunakan bantuan program ETABS untuk menganalisa dan membandingkan nilai output syarat-syarat bangunan tahan gempa serta membandingkan gaya-gaya dalam kolom tengah dan kolom pinggir.

\section{Hasil dan Pembahasan}

Hasil analisis yang diperoleh dari program ETABS antara lain waktu getar alami strukur, geser dasar, simpangan horisontal struktur dan gaya-gaya dalam kolom tengah dan kolom pinggir.

Hasil analisis tersebut digunakan dalam perancangan struktur serta untuk menarik kesimpulan tentang perubahan simpangan horisontal dan perubahan kapasitas elemen balok-kolom dengan variasi tata letak pemasangan dinding geser pada kasus struktur beton dalam portal tiga dimensi.

\subsection{Waktu Getar Alami Fundamental}

Waktu getar yang diambil adalah waktu getar pada mode pertama Tabel 1 memperlihatkan rekap nilai pendekatan waktu getar alami struktur yang dihitung menggunakan program bantu ETABS untuk semua model penempatan dinding geser.

diantara batas bawah dan batas atas tersebut. Waktu getar yang diambil untuk dibandingkan adalah waktu pada mode pertama karena mode pertama merupakan pola pergoyangan yang pertama menerima gempa dan umumnya waktu paling besar adalah pada mode pertama. Untuk lebih jelas bisa dilihat pada Gambar 2. 
Tabel 1. Hasil waktu getar alami fundamental berbagai model dinding geser

\begin{tabular}{|c|c|c|c|c|c|}
\hline \multirow{3}{*}{ Model } & \multirow{3}{*}{$\begin{array}{l}\text { Waktu } \\
\text { getar } \\
\text { (Tc) }\end{array}$} & \multicolumn{2}{|c|}{ SNI } & \multirow{3}{*}{ Kontrol } & \multirow{3}{*}{ Keterangan } \\
\hline & & $\begin{array}{c}\text { Batas } \\
\text { bawah }\end{array}$ & $\begin{array}{c}\text { Batas } \\
\text { atas }\end{array}$ & & \\
\hline & & $\mathrm{Ta}$ & Cu.Ta & & \\
\hline Model 1 & 1,10 & 0,7762 & 1,0867 & Not Oke & Pakai Cu.Ta \\
\hline Model 2 & 1,108 & 0,7762 & 1,0867 & Not Oke & Pakai Cu.Ta \\
\hline Model 3 & 1,264 & 0,7762 & 1,0867 & Not Oke & Pakai Cu.Ta \\
\hline Model 4 & 0,965 & 0,7762 & 1,0867 & oke & Pakai Tc \\
\hline Model 5 & 0,957 & 0,7762 & 1,0867 & oke & Pakai Tc \\
\hline Model 6 & 0,995 & 0,7762 & 1,0867 & oke & Pakai Tc \\
\hline
\end{tabular}

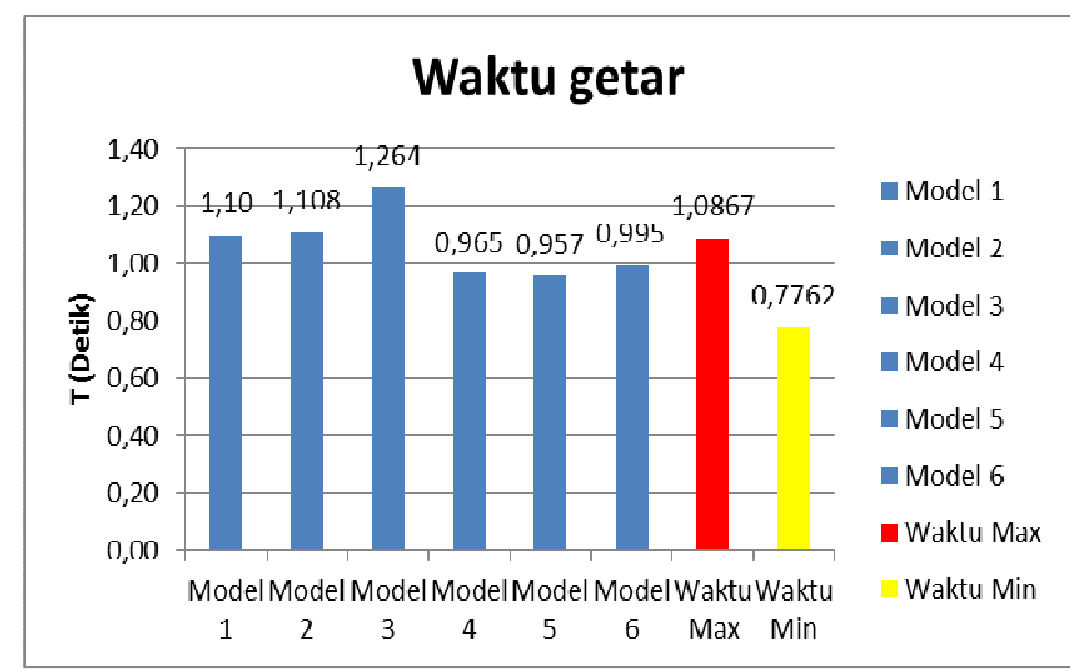

Gambar 2 Diagram batang hasil waktu getar alami fundamental

Dari gambar 2 dan dari tabel 1 dapat dilihat bahwa waktu getar model 1, 2 dan 3 tidak berada diantara batas bawah dan batas atas, karena penempatan dinding geser model 1, 2 dan 3 tidak simetris menjadi penyebab nilai waktu getar tidak memenuhi syarat SNI. Karena hasil model 1, 2 dan 3 melebihi batas atas yang disyaratakan SNI berarti gedung dengan penempatan dinding geser pada model 1, 2 dan 3 bergerak lebih fleksibel sehingga model 1, 2 dan 3 dapat digunakan dengan terlebih dahulu merivisi kembali waktu getar pada analisis. Pada tabel 1 juga menunjukkan bahwa adanya perbedaan nilai waktu getar yang dialami struktur gedung, berarti dengan adanya perbedaan penempatan dinding geser memberikan kekakuan yang berbeda pula terhadap gedung sehingga bisa dilihat model 5 memiliki nilai waktu getar yang lebih kecil dari pemodelan dinding geser yang lain. Tetapi dengan hanya melihat bahwa model 5 memiliki kekakuan yang tinggi karena memiliki waktu getar yang realtif pendek tidak menjamin anailis seperti displacement dan geser dasar serta gaya-gaya dalam kolom juga akan kecil ataupun memenuhi sehingga perlu dilihat parameterparameter yang lain seperti $d r f i t$ dan base shear. 


\subsection{Drift (Simpangan Antar Lantai)}

Hasil analisis struktur dalam penelitian ini didapatkan nilai simpangan antar lantai. Berdasarkan (SNI 03-1726-2012) untuk simpangan antar lantai tingkat desain $(\Delta)$ tidak boleh melebihi simpangan antar lantai tingkat ijin $(\Delta a) / \rho$. Drift merupakan hasil pengolahan dari nilai selisih displacement tiap lantai yang diperoleh dari ETABS yang kemudian dikalikan dengan faktor amplifikasi respon untuk selanjutnya dibagi dengan nilai faktor ketamaan gempa. Oleh karena itu simpangan antar lantai ijin $(\Delta \mathrm{a})$ ditentukan dengan rumus $0,020 \mathrm{hsx}$, dimana hsx adalah tinggi tingkat di bawah tingkat $\mathrm{x}$, yaitu $4000 \mathrm{~mm}$. Maka diperoleh $\Delta \mathrm{a}=$ $(0,020 \times 4000) / 1,3=61,54 \mathrm{~mm}$. . Untuk grafik hasil simpangan antar lantai (drift) pad arah $\mathrm{X}$ diperlihatkan pada gambar 3 .

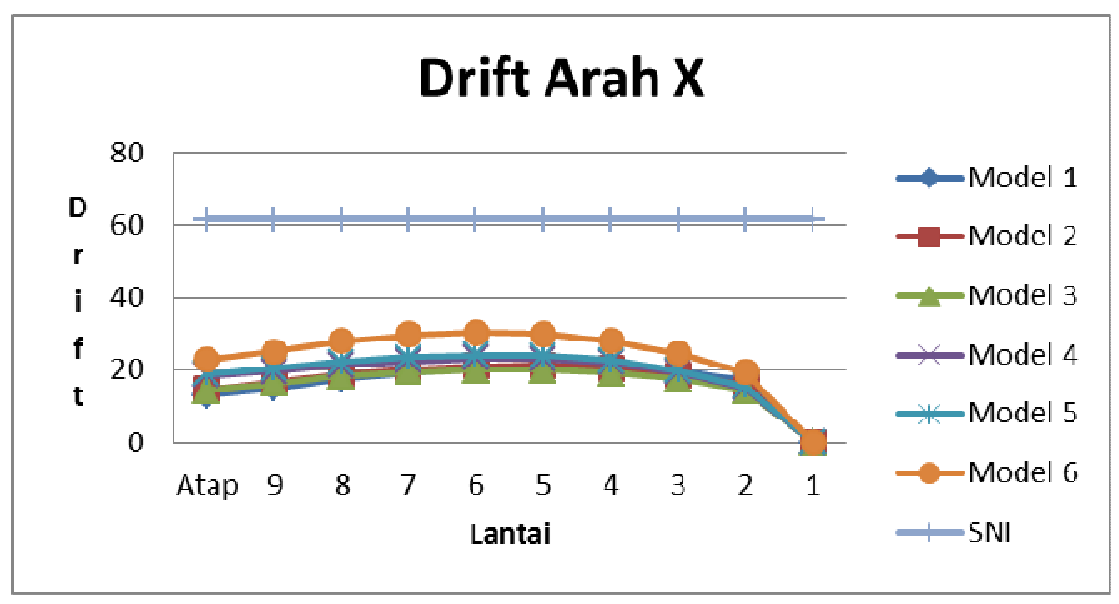

Gambar 3 Diagram hasil drift arah X

Untuk grafik hasil simpangan antar lantai (drift) pad arah Y diperlihatkan pada Gambar 4.

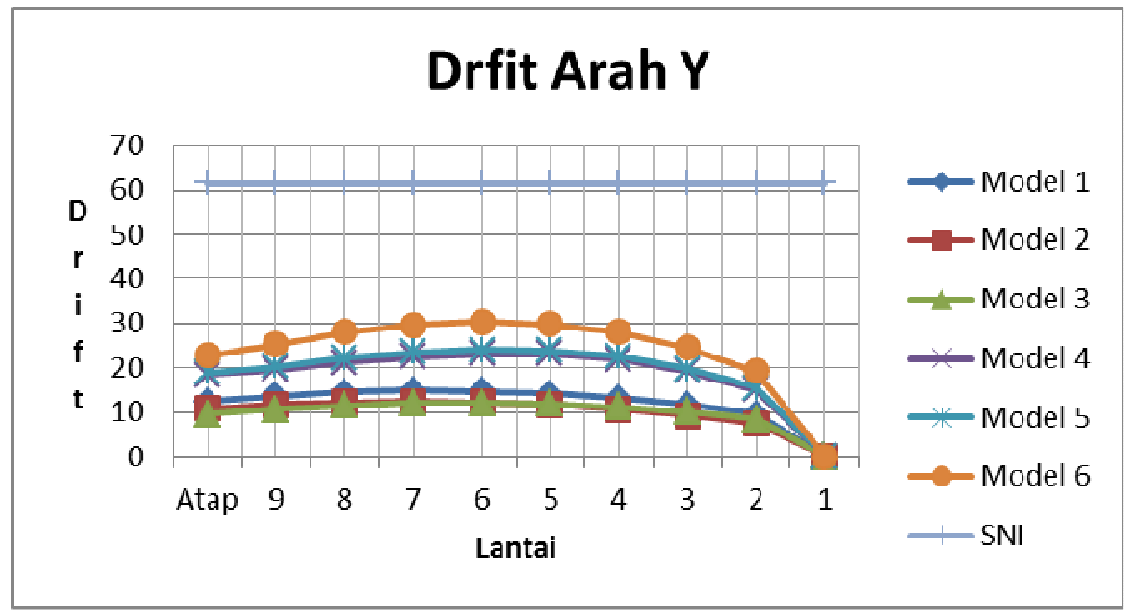

Gambar 4 Diagram hasil drift arah Y 
Dari Gambar 4 dapat dilihat bahwa simpangan antar lantai untuk semua model terpenuhi, tidak ada satupun model yang melewati nilai drift izin. Dengan nilai simpangan antar lantai yang terpenuhi sehingga semua model memiliki nilai yang simpangan yang kecil dan aman pada saat menerima beban lateral.

\subsection{Gaya-gaya Dalam Kolom}

Hasil analisis program ETABS menunjukkan nilai gaya-gaya dalam kolom struktur dengan berbagai pemodelan dinding geser. Perbandingan gaya dalam yang akan dilakukan yaitu antara struktur kolom pinggir dan struktur kolom tengah. Gaya dalam yang akan dibandingkan hanya gaya momen saja karena gaya momen yang berpegaruh terhadap desain penampang kolom. Untuk grafik hasil gaya momen pada kolom tengah diperlihatkan pada Gambar 5.

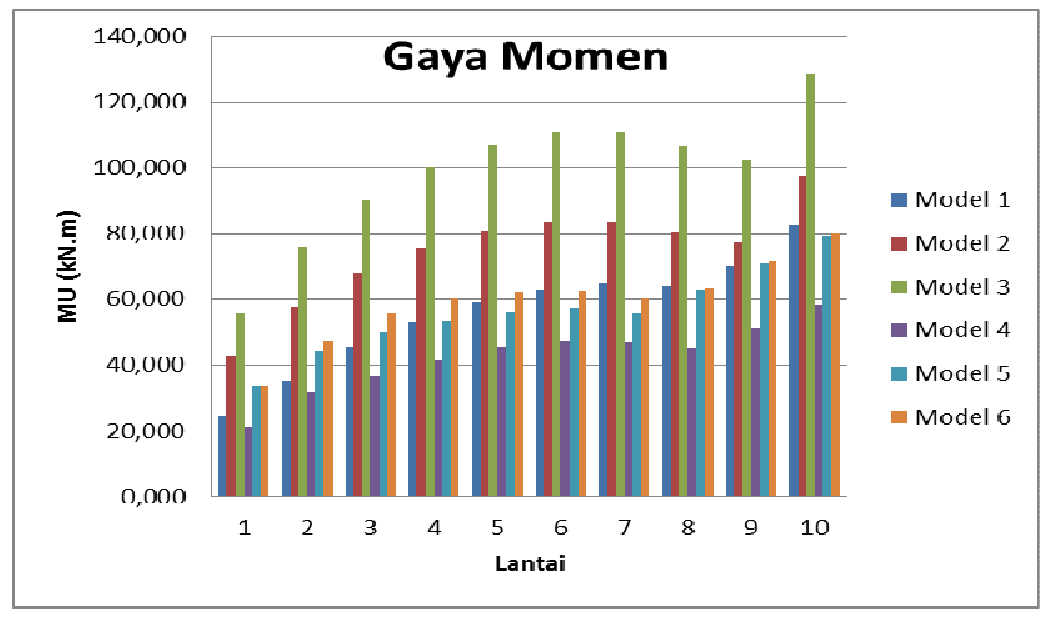

Gambar 5 Diagram gaya momen kolom tengah

Diagram batang momen diatas menunjukkan bahwa terhadap kolom tengah dinding geser yang tidak simetris menghasilkan nilai momen yang besar yang berarti akan berpengaruh pada kebutuhan tulangan yang semakin besar. Hasil ini sesuai dengan hasil yang disajikan analisis gempa yaitu hasil waktu getar dan simpangan lantai dimana dinding geser yang simetris menunjukkan hasil yang aman. Dari hasil ini dapat dilihat bahwa untuk sebuah gedung sangat direkomendasi penempatan dinding geser yang simetris dari pada dinding geser yang tidak simetris seperti model 4, model 5, model 6.

Diagram batang momen kolom pinggir pada Gambar 6 menunjukkan hasil yang hampir sama terhadap momen kolom tengah yaitu dinding geser yang tidak simetris menghasilkan nilai momen yang besar yang berarti akan berpengaruh pada kebutuhan tulangan yang semakin besar. Sedangkan terhadap kolom pinggir dinding geser yang simetris akan menghasilkan nilai momen yang kecil yang berarti akan berpengaruh pada kebutuhan tulangan yang sedikit. Dari hasil ini dapat dilihat bahwa untuk sebuah gedung sangat direkomendasi penempatan dinding geser yang simetris dari pada dinding geser yang tidak simetris. 

Gambar 6.

Untuk grafik hasil gaya momen pada kolom pinggir diperlihatkan pada

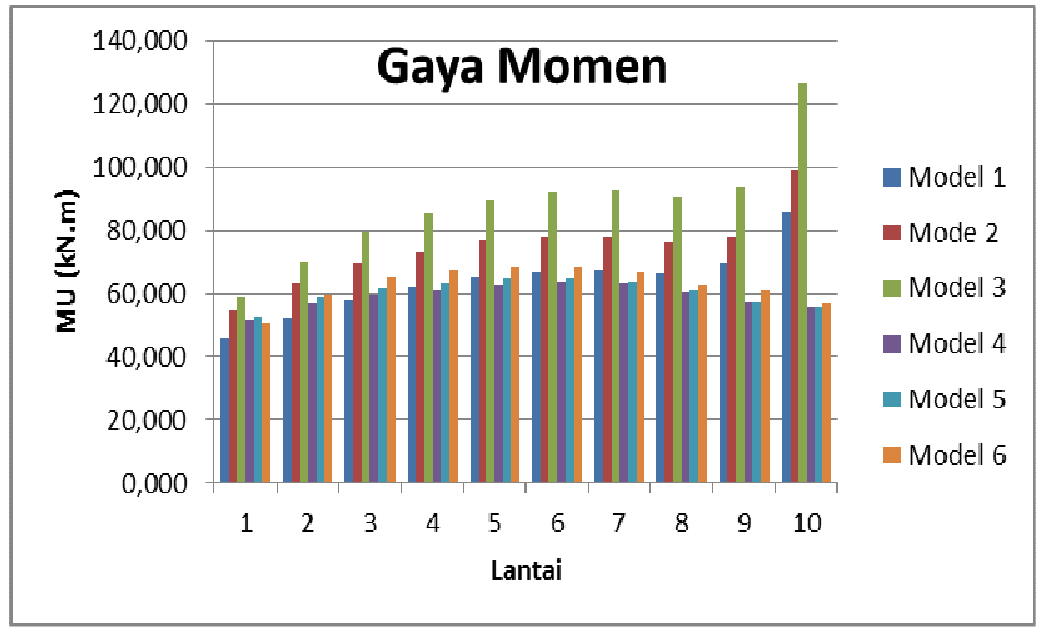

Gambar 6. Diagram gaya momen kolom pinggir

\section{Kesimpulan dan Saran}

\subsection{Kesimpulan}

Berdasarkan hasil penelitian yang telah dilakukan dapat diambil kesimpulan sebagai berikut:

1. Pemasangan dinding geser pada struktur gedung dengan berbagai model variasi tata letak dinding geser yang berbeda-beda seperti yang telah dibahas akan memberikan hasil yang berbeda-beda pula. Dari semua parameter respon gempa seperti waktu getar, simpangan antar lantai serta gaya-gaya dalam kolom tengah dan pinggir menyajikan bahwa pemodelan dinding geser model 4, 5 dan 6 yaitu dinding geser yang simetris menunjukkan nilai yang aman dari semua respon gempa dan menghasilkan gaya-gaya dalam yang kecil daripada pemodelan dinding geser model 1, 2 dan 3 yaitu dinding geser yang tidak simetris sehingga dinding geser yang simetris pada bangunan paling aman dan stabil untuk digunakan.

2. Dinding geser yang ditempatkan tidak simetris pada bangunan akan memberikan waktu getar yang lebih panjang sehingga tidak memenuhi batas atas waktu dari (SNI 03-1726-2012) sedangkan dinding geser dengan posisi simetris akan memberikan nilai yang hampir sama dan masih masuk diantara batas bawah dan batas atas yang diatur dalam (SNI 03-1726-2012) dan pada pemodelan 5 memiliki waktu yang paling kecil diantara model lain yaitu sebesar 0,957.

3. Semua nilai simpangan antar lantai pada semua model tidak melebihi nilai yang disyaratkan (SNI 03-1726-2012) yaitu sebesar 61,5mm. Nilai simpangan antar lantai yang paling besar pada semua model terdapat pada lantai ke 6 dan pada arah X. Nilai simpangan atar lantai terbesar yaitu pada arah X model ke 6 dengan nilai $30,322 \mathrm{~mm}$ dan yang paling kecil terdapat pada arah Y model 3 dengan nilai $12,128 \mathrm{~mm}$. Penempatan dinding geser simtersi akan memberikan hasil simpangan antar lantai yang sama dari nilai simpangan arah $\mathrm{X}$ dan simpangan arah Y. 
4. Pada pemodelan simetris yaitu model 1 , model 2 , dan model 3 menunjukkan nilai gaya momen yang kecil dari pemodelan yang tidak simetris. Gaya momen yang kecil tedapat pada kolom tengah dan kolom pinggir. Hal ini menekankan bahwa penempatan dinding geser yang simetris sangat cocok digunakan pada sebuah gedung karena memiliki parameter yang aman dari yang disyaratkan (SNI 03-1726-2012) dan dinding geser yang simetris memiliki gaya dalam yang kecil yang berarti akan berpengaruh pada kebutuhan gaya desain yang kecil.

\subsection{Saran}

Penelitian ini mempunyai saran bila dilakukan penelitian dimasa yang akan datang sebagai berikut:

1. Perlunya dilakukan penelitian lebih lanjut untuk pengecekan torsi pada penempatan dinding geser yang tidak simetris serta perlunya pengecekan kapasitas balok kolom sehingga hasil lebih akurat.

2. Ketelitian dalam menggunakan software harus diperhatikan agar dapat menghasilkan analisa yang sesuai dengan keadaan di lapangan nanti dan harus harus dicoba dengan softwere struktur lain seperti SAP2000, STAAD Pro, dll.

3. Perlu dilakukan penelitian untuk variasi dinding geser dan variasi dimensi dinding geser yang digunakn pada bangunan yang tidak simetris serta perlunya dilakukan untuk wilayah gempa yang berbeda.

4. Sebagai tambahan analisis agar lebih akurat sebaiknya dilakukan analisis pushover untuk mengetahui perilaku atau pola keruntuhan suatu bangunan serta pengecekan torsi dengan berbagai variasi tata letak dinding geser.

\section{Daftar Kepustakaan}

Andalas, G. (2016). Analisis Layout Shearwall Terhadap Perilaku Struktur Gedung. Jurusan Teknik Sipil Fakultas Teknik Universitas Lampung., 1(1), 491-502.

Juwana, J. S. (2005). Panduan Sistem Bangunan Tinggi. (Hilarius WIbi Hardani, Ed.). Jakarta: Erlangga.

Badan Standardisasi Nasional SNI 03-1726-2012 (2012). Tata cara perencanaan ketahanan gempa untuk struktur bangunan gedung dan non gedung. In Bandung: Badan Standardisasi Indonesia (p. 149). Retrieved from www.bsn.go.id

Pauley, T., Priestley, M. J. N., Paulay, T., \& Priestley, N. (1992). Seismic Design of Reinforced Concrete and Masonry Buildings. John Wiley \& Sons, Inc. https://doi.org/10.1002/9780470172841.fmatter

Badan Standardisasi Nasional SNI 03-2847-2013. (2013). Persyaratan Beton Struktural untuk Bangunan Gedung. In Bandung: Badan Standardisasi Indonesia (pp. 1-265). 